\title{
Effectiveness of Chilled ceiling assisted by intermittent personalized ventilation for active contaminants' confinement and energy savings
}

\author{
D. Al Assaad ${ }^{1}$, K. Ghali ${ }^{1}$ and N. Ghaddar ${ }^{1}$ \\ ${ }^{1}$ Department of Mechanical Engineering \\ American University of Beirut \\ P.O. Box 11-0236, Beirut 1107-2020, Lebanon \\ Phone/Fax number: +961 1340460 , Ext.3438, e-mail: ka04@aub.edu.lb
}

\begin{abstract}
The integration of intermittent personalized ventilation in office spaces equipped with chilled ceiling has been proven to enhance comfort and provide satisfactory indoor air quality. However, in the case where the occupant using the personalized ventilator is infected, the turbulence of the intermittent personalized ventilation jet could enhance contaminant spread and compromise the indoor air quality in the space. In this work, an office space equipped with a chilled ceiling and intermittent personalized ventilation was modelled using a validated CFD model. The intermittent jet was supplied towards an infected occupant. The frequency and average flow rate that could minimize particle spread in the space were investigated. It was found that the intermittent personalized ventilator should be operated at a frequency of $0.3 \mathrm{~Hz}$ and an average flow rate of $3.5 \mathrm{~L} / \mathrm{s}$. These conditions confined the particles to their source of generation while still providing comfort for the infected occupant.
\end{abstract}

\section{Key words}

Personalized ventilation, chilled ceiling, active contaminants, energy savings

\section{Introduction}

Heating ventilation and air conditioning (HVAC) systems are integrated within building envelopes to ensure the wellbeing of occupants by providing good indoor air quality (IAQ) [1]. IAQ is highly dependent on the concentration of pollutants present inside the space. Indoor environments are polluted by passive contaminants and especially by active contaminants (smoke, dust, bacteria) [2]. Active contaminants are mostly generated by human respiratory activities (coughing, sneezing...) and can be transmitted to other occupants through direct inhalation or indirectly through hand to mouth contact. Infection by active contaminants poses a danger to human health and can increase the risk of death, especially if contaminants carry pathogens [3]. Therefore, HVAC systems should be able to confine active particles to their generation source and prevent their spread in the space in order to prevent healthy occupant contamination.

A conventional air distribution system, widely used in the building sector is the chilled ceiling (CC) system. CC systems usually consist of a metal panel installed at ceiling height and cooled by chilled water circulating in pipes. They provide thermal comfort for occupants through radiative and convective heat exchange with heated surfaces and are characterized by their quiet operation [4]. Using computational fluid dynamics (CFD), Catalina et al. [5] modeled a test room equipped with a CC for thermal comfort investigation. Their results showed that small vertical temperature gradients were found in the room as well as small momentum and good values of thermal comfort. $\mathrm{CC}$ are also beneficial in terms of saving energy. In fact, the heat removed from the occupant by the $\mathrm{CC}$ allows it to maintain the room at higher ambient temperatures than typical HVAC systems for similar comfort. This reduces energy costs by decreasing the cooling load. Numerical simulations of rooms equipped with $\mathrm{CC}$ showed a $10 \%$ reduction in energy consumption [6].

Even though the $\mathrm{CC}$ is an efficient system in providing thermal comfort, it has its disadvantages. In fact, CC systems can only remove a limited load from the space and can compromise IAQ since they don't bring in fresh air into the space to dilute the present contaminants. Consequently, CC systems cannot function as standalone systems and need to be assisted by additional HVAC units that can compensate its shortcomings. A viable option are the personalized ventilation units (PVU) which are localized energy efficient HVAC systems. PVU target the personal environment of the occupant by supplying cool fresh air directly to the breathing zone [7]. Hence, PVU can enhance thermal comfort as well as provide good breathable air quality. Moreover, these systems are cheap and can be either integrated into the office furniture or constitute personal systems that can be incorporated into human clothing.

In more recent applications, the cool fresh air supplied by the PVU was modified by fluctuating the supply flow rate between a minimum and a maximum at a certain characteristic frequency [8]. The intermittency of the PVU system was found to improve thermal 
comfort compared to steady flow rates [9]. Al-Assaad et al. [10] studied the effectiveness of intermittent desk mounted PVU in providing comfort and protecting occupants against passive contaminants. It was found that a frequency of $0.5 \mathrm{~Hz}$ and an average flow rate of $7.5 \mathrm{~L} / \mathrm{s}$ were able to provide a compromise between comfort and IAQ. However, the ability of the intermittent desk mounted PVU system in confining particle spread within the office space was not considered. In fact, the intermittency of the PVU flow increases turbulence considerably in the occupant surrounding, especially with increasing frequency. Moreover, the CC system increases turbulence furthermore due to temperature differences between the ceiling and heated surfaces in the room. Therefore, in case the occupant using the intermittent PVU was infected, the increased turbulence in the surrounding environment could degrade air quality in the room macroclimate considerably. This risks the well-being and increases the exposure of other healthy occupants that may leave their workstations for certain durations of time and move around in the office space.

In this study, an office space conditioned by a CC system and coupled with a desk mounted intermittent PVU is considered. In the office, an infected occupant using the PVU is considered. The effectiveness of the intermittent PVU in confining particle spread from the infected person will be studied using an experimentally validated transient 3D CFD model. A parametric study is then conducted to recommend intermittent PVU operating parameters (frequency and average flow rate) that are able to minimize the spread of particles while still maintaining the comfort of the PVU user. Based on the obtained operating conditions, the energy savings of the system will be computed compared to a steady PVU+CC for similar comfort.

\section{Problem description}

The study considers a typical office space of dimensions $3.4 \mathrm{~m} \times 3.4 \mathrm{~m} \times 2.8 \mathrm{~m}$. The office is equipped with a workstation and an occupant represented by a thermal manikin. The room is equipped with a wooden door $(2 \mathrm{~m} \times 1 \mathrm{~m})$ and the office is considered to have small apertures $(0.5 \mathrm{~m} \times 0.6 \mathrm{~m})$. Several layers of brick and concrete are considered to constitute the room walls. The inner layer is made out of a Gypsum board having a thermal conductivity of $0.161 \mathrm{~W} / \mathrm{m} . \mathrm{K}$. The total load to be removed is a typical load of $40 \mathrm{~W} / \mathrm{m}^{2}$ due to computer, lighting, occupants [8]. The office is conditioned by a $\mathrm{CC}$ system. The CC system is coupled with an intermittent PVU system. The PVU nozzle is mounted on the desk, has a diameter outlet of $5 \mathrm{~cm}$ and located at $40 \mathrm{~cm}$ from the occupant. Figure 1 illustrates the considered space. The PVU has its own air handling unit (AHU) supplying 100\% fresh filtered air. The concentration of active and passive particles $\left(\mathrm{NO}_{2}, \mathrm{CO} \ldots\right)$ in the supplied air is negligible and the concentration in $\mathrm{CO}_{2}$ is $450 \mathrm{ppm}$. The PVU horizontal jet is supplied towards the occupant BZ at a characteristic average flow rate and frequency $f$.
The confinement of particles to their location source is assessed using the confinement index and concentration gradient index in equation (1) and (2) respectively:

$$
\begin{aligned}
& C I=\frac{\text { Number of particles confined in the microclima te }}{\text { Number of particles generated }} \\
& \Delta C=\left|C_{\text {Right,macro }}-C_{\text {Left.macro }}\right|
\end{aligned}
$$

The indirect contamination of healthy occupants with active particles, due to deposition and consequent hand to mouth contact, is assessed with the deposited fraction $D F r$. The deposited fraction is the number of particles deposited on a surface over the generated particles number at the source.

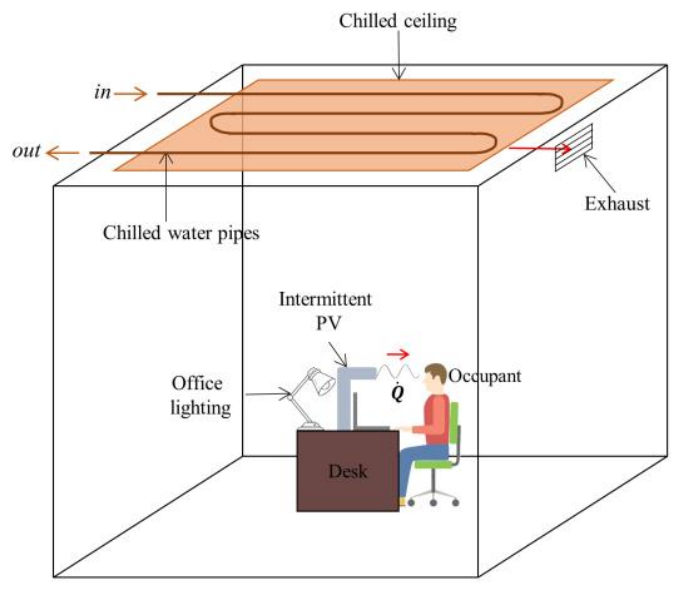

Fig. 1. Schematic of the office space with CC and PVU.

\section{CFD model}

In this work, there are complex airflow field behavior that are taking place due to the presence of the $\mathrm{CC}$ and the PVU systems. In fact the CC establishes a gradient of temperature in the space which leads to unstable stratification and buoyancy which in turn results in high turbulence intensities in the space. Moreover, the transient PVU jet is another factor which increases turbulence in the microenvironment surrounding the occupant. In addition, there are several heat sources in the space giving rise to thermal plumes as well as generation of active particles which are subject to dispersion, escape or deposition. This affects the airflow field variables such as velocity, temperature, turbulence intensity as well as particles' concentration. Consequently, a 3D computational fluid dynamics model (CFD) is needed to resolve for these different fields. A CFD tool is used to precisely resolve the different variables. The commercial software ANSYS Fluent [12] was used to solve the momentum, energy equations, pressure velocity coupling as well as the turbulence, dissipation rate equations and discrete phase models... The domain used in Fluent can be seen in Fig. 2. For exact predictions of flow behavior, the space should be appropriately meshed (Fig $2 \mathrm{a}$ and b). Therefore, inflation layers are created around the boundaries such that the 
range of the dimensionless wall number $y^{+}$is $[0.8-4]$ [13]. The considered space is meshed into tetrahedral elements with face sizing applied at the boundaries (thermal manikin: $1.5 \mathrm{~cm}$, walls: $2 \mathrm{~cm}$. The final mesh had 5119220 elements with 951942 nodes that ensured a grid independent solution (maximum relative error of less than $5 \%$ ).
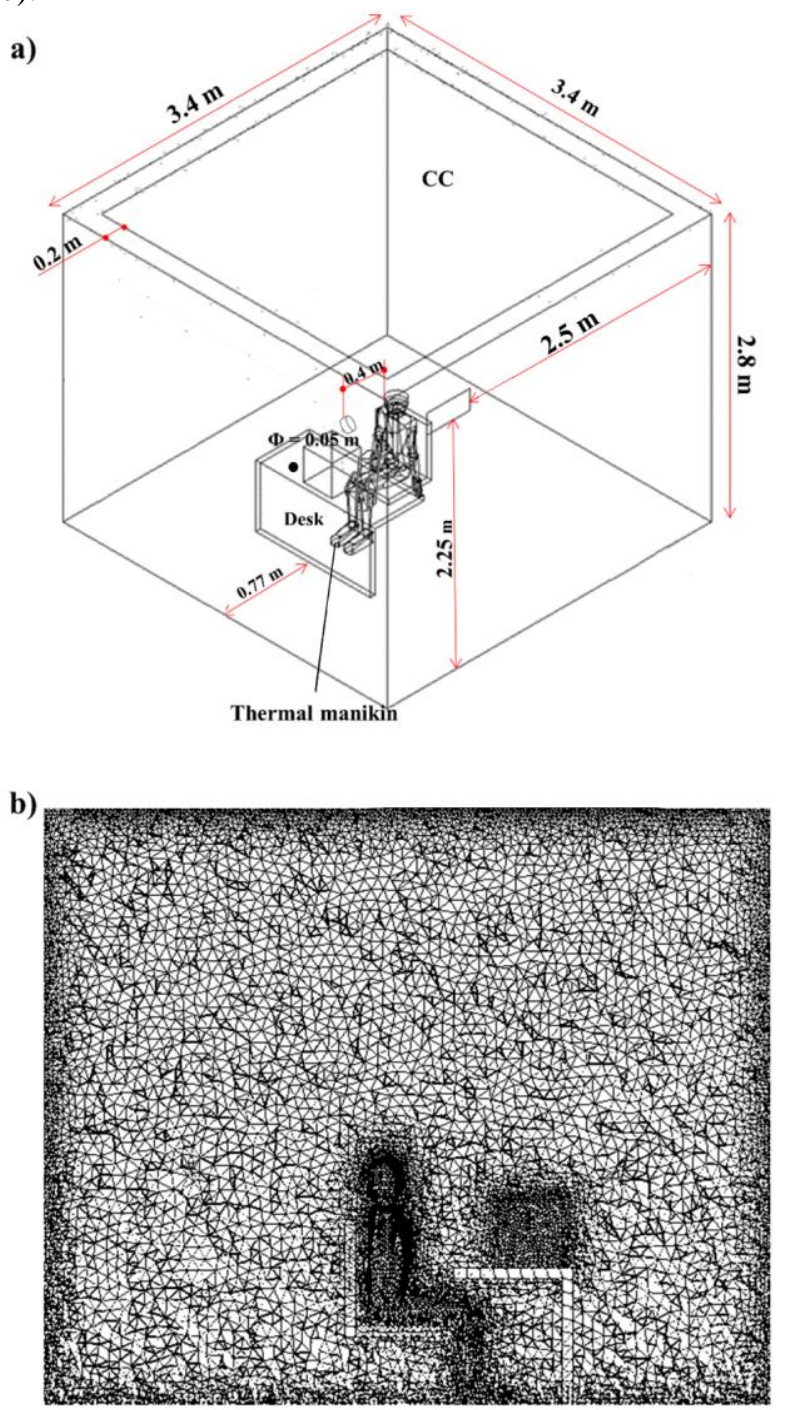

Fig. 2. Illustration of: (a) the physical domain as seen on ANSYS Fluent, (b) the corresponding mesh.

Due to the turbulence created by the intermittent PVU jet and the CC, the RNG $\mathrm{k}-\varepsilon$ model was used to model turbulence [14]. Due to small density variations, the Boussinesq approximation is used to account for buoyancy effects. The S2S radiation model is implemented to account for the radiation between $\mathrm{CC}$ and heated surfaces. The discretization schemes for the different variables (momentum, energy, $\mathrm{k}, \varepsilon$, species...) are presented in Table 1. Numerical convergence is reached for scaled residuals of less than $10^{-5}$ for all quantities except energy where it should be less than $10^{-7}$.

Table 1. Flow field variables and the different discretization schemes

\begin{tabular}{|c|c|}
\hline Flow Field variables & Scheme \\
\hline $\begin{array}{l}\text { momentum, energy, } \mathrm{k}, \varepsilon \text { and } \\
\text { turbulence equations, species }\end{array}$ & second order upwind scheme \\
\hline
\end{tabular}

\begin{tabular}{|l|c|}
\hline transport & \\
\hline pressure equation & "PRESTO!" scheme \\
\hline Transient term & second order implicit time \\
& stepping scheme, time step of \\
& 0.05 seconds \\
\hline Pressure velocity coupling & PISO scheme \\
\hline
\end{tabular}

The discrete phase model (DPM) was used to track particles trajectories in the space. The DPM model solves the second law of Newton and accounts for the different forces acting on the particle (drag, lift, gravity, thermophoretic forces...). The Lagrangian technique was used to track the particles' trajectories in the space along with the discrete random walk (DRW). In order to get physical results, the boundary conditions should be properly selected in the CFD model. The PVU is set as velocity inlets with a transient velocity (user defined (UDF) function). The PVU is characterized with an inlet temperature of $22^{\circ} \mathrm{C}$. The exhaust grills are chosen as a pressure outlet with zero gauge pressure. Solid surfaces (walls, table chair, occupant...) are set as walls with zero velocity with some of them emitting a constant heat flux such as the computer $(93 \mathrm{~W})$, the occupant $(100 \mathrm{~W})$ and the walls $\left(10 \mathrm{~W} / \mathrm{m}^{2}\right)$. The $\mathrm{CC}$ is assigned as a wall with constant temperature of $20^{\circ} \mathrm{C}$ assuring a temperature of $26^{\circ} \mathrm{C}$. As for discrete phase modeling (DPM) boundary conditions, all solid surfaces are considered as trap boundary condition to account for deposition. The exhaust is assigned an escape boundary condition since particles exit the space through the exhaust grills. Remaining trajectories are tracked in the space. The considered occupant is contaminated and is generating active particles at a seated height of $1.1 \mathrm{~m}$ in the horizontal direction. The particles are generated at a velocity of $1 \mathrm{~m} / \mathrm{s}$, a mean flow rate of $8.4 \mathrm{~L} / \mathrm{min}$ and a mass flow rate of $5 \times 10^{-5} \mathrm{Kg} / \mathrm{s}$. Many active particles can be present in the space, with diameters ranging between $0.1 \mu \mathrm{m}$ and $10 \mu \mathrm{m}$ [11]. In this study, an average particle diameter of $1 \mu \mathrm{m}$ was considered. The plane of particles' generation as well as the right and left macroclimate are shown in Figure 3. 
a)

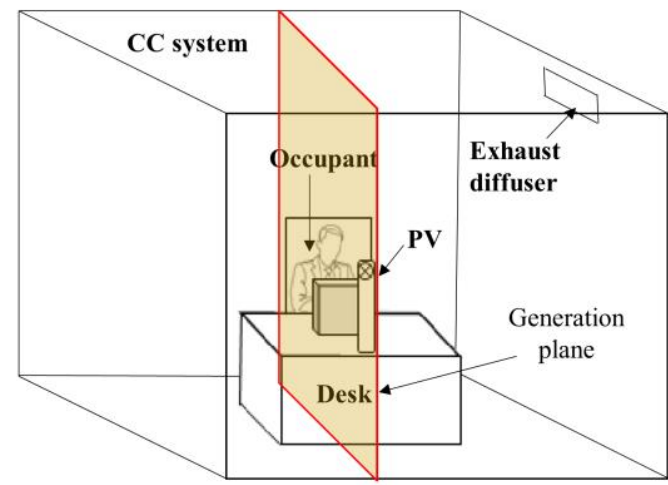

b)

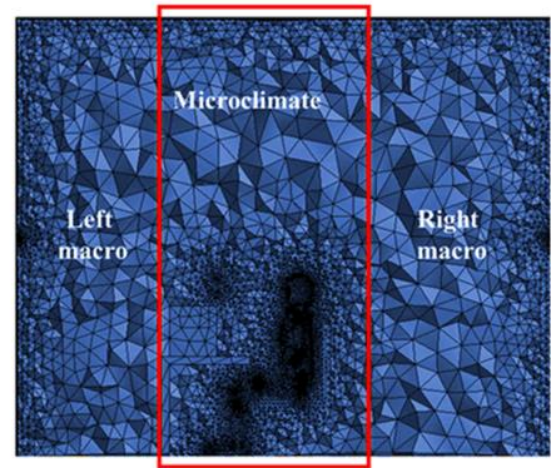

Fig. 3. Illustration of: (a) the considered space with the particle generation plane, (b) the right and left macroclimates.

\section{Results and discussion}

The CFD model of the intermittent PVU+CC system was previously validated in the work of $\mathrm{Al}$ Assaad et al. [11]. The model is simulated for three typical frequencies found in indoor spaces $(0.3 \mathrm{~Hz}, 0.5 \mathrm{~Hz}, 1 \mathrm{~Hz})$ and three typical flow rate $(3.5 \mathrm{~L} / \mathrm{s}, 5 \mathrm{~L} / \mathrm{s}$ and $7.5 \mathrm{~L} / \mathrm{s})$. The $\mathrm{CC}$ has a temperature of $20^{\circ} \mathrm{C}$ and assures a background temperature of $26^{\circ} \mathrm{C}$ and the PVU supply temperature is set to $22^{\circ} \mathrm{C}$. Species and particles are considered to be present in the room. Active particles are generated at a seated occupant height of $1.1 \mathrm{~m}$ from the occupant mouth at a flow rate of $8.4 \mathrm{~L} / \mathrm{min}$. The active contaminants are 1 $\mu \mathrm{m}$ particles belonging to the inhalable range found indoors. Table 2 represents the average values of $C I, \Delta C$ and $D F r$ as a function of frequency and average PVU flow rate.

Figure 4 represents the variation of $C I, \triangle C$ and $D F r$ as a function of frequency for an average PVU flowrate of $5 \mathrm{~L} / \mathrm{s}$. It can be seen that when the frequency increases from $0.3 \mathrm{~Hz}$ to $1 \mathrm{~Hz}$, at a fixed average flow rate, the average $C I$ decreases while the $\Delta C$ and $D F r$ increase. This means that particles are migrating from the microenvironment and depositing on the surfaces nearby the occupant (desk, chair, body). This behavior can be explained by the $44 \%$ increase in turbulence intensity when the frequency increases. The increases turbulence increases the agitation of particles causing them to migrate away from their source or deposit near the occupant. This can be further seen in Fig. 5 which represents the contours of particle concentrations for an average flow rate of $5 \mathrm{~L} / \mathrm{s}$ and a frequency of $0.3 \mathrm{~Hz}$ and $1 \mathrm{~Hz}$. Therefore to minimize particle dispersion, it is better off to operate the PVU at the lowest frequency of $0.3 \mathrm{~Hz}$.

Table 2 The average values of $C I, \Delta C$ and $D F r$ as a function of frequency and average PVU flow rate

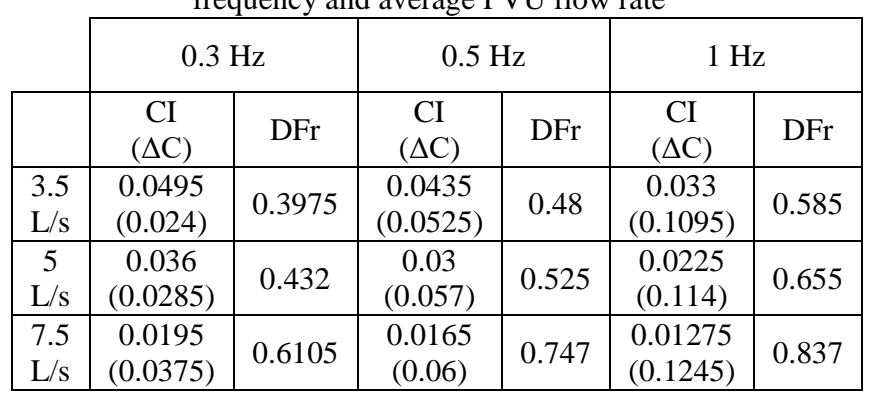

Figure 6 represents the effect of PVU varying flow rate on $C I, \Delta C$ and $D F r$ for a frequency of $0.3 \mathrm{~Hz}$ and a particle size of $1 \mu \mathrm{m}$. The average PVU flow rate parameter determines how much fresh air is reaching the occupant. It is shown that when the average PVU flow rate increases at a fixed frequency of $0.3 \mathrm{~Hz}, C I$ decreases, while $\Delta C$ and $D F r$ increase. This is due to the fact that with increasing fresh air flow towards the generating occupant, part of the particles is pushed downwards by the flow due to their small horizontal momentum. The other fraction of particles is blown away by the high-momentum flow and is forced to leave the microclimate and spread in the space. It is also reported that the rate of increase of $\mathrm{DFr}$ is larger than the rate of increase of $\Delta C$ which means that most particles are deposited in the microclimate. Therefore, the average flow rate is not an important parameter as the PVU frequency. However, it is favorable to operate at low average flow rate of $3.5 \mathrm{~L} / \mathrm{s}$.

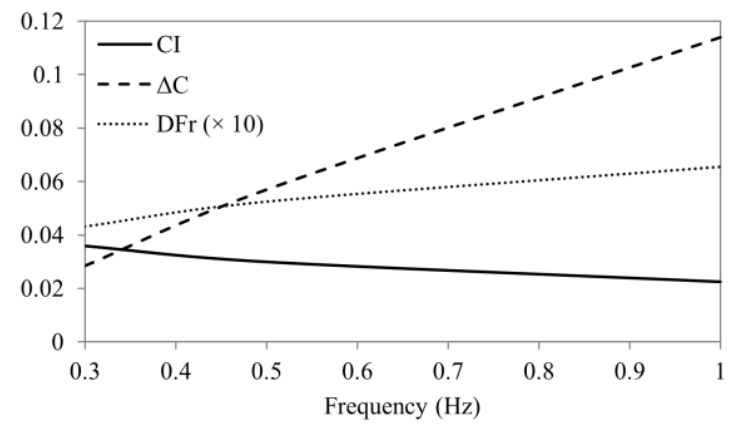

Fig. 4. $C I, \triangle C$ and $D F r$ as a function of frequency for a PVU average flow rate of $5 \mathrm{~L} / \mathrm{s}$. 


\section{a) $0.3 \mathrm{~Hz}$}

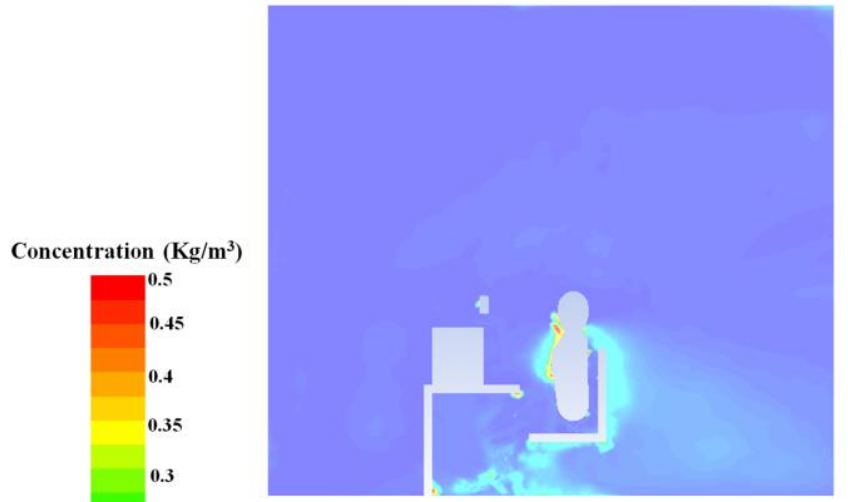

b) $1 \mathrm{~Hz}$

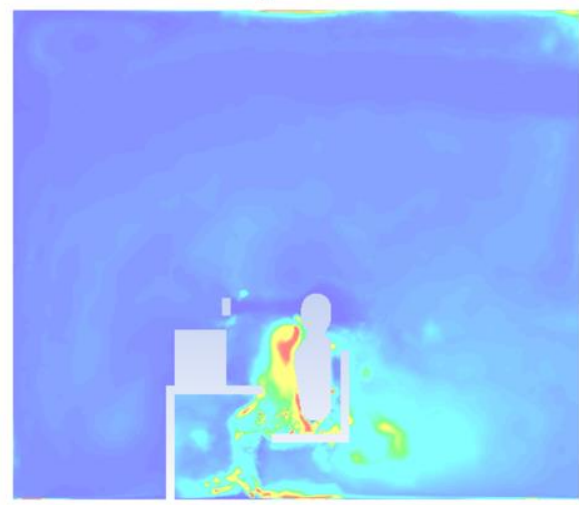

Fig. 5 Illustration of particle concentration contours for an average PVU flow rate of $5 \mathrm{~L} / \mathrm{s}$ for a frequency of: a) $0.3 \mathrm{~Hz}, \mathrm{~b}$ )

$1 \mathrm{~Hz}$.

Note that the operating PVU conditions of $0.3 \mathrm{~Hz}$ and 3.5 $\mathrm{L} / \mathrm{s}$ bring comfort to the infected occupant according to the thermal comfort study of $\mathrm{Al}$ Assaad et al. [8]. In order to calculate the energy savings of the intermittent PVU+CC system, the fan power consumption as well as the cooling capacity of an intermittent PVU should be calculated and compared to a steady case. The reference steady state condition is a PVU flow rate of $4.2 \mathrm{~L} / \mathrm{s}$ that provides same comfort. The correlation of Keblawi et al. [14] was used to calculate fan power consumption:

$P_{f a n}=P_{\text {ref }}\left(\frac{m_{\text {fan }}}{m_{\text {fañef }}}\right)^{3}$

Where $m_{f a n}^{*}$ is the fan mass flow rate, $P_{\text {fan }}$ is the fan power consumption, $P_{\text {ref }}$ and $m_{\text {faniref }}$ are the nominal power consumption and mass flow rate respectively for steady state PVU operation. To account for time variation, the power was averaged over one period. It was found that a transient fan operation $(2 \mathrm{~W})$ was slightly higher than a steady case $(1.62 \mathrm{~W})$. However, the decrease in cooling capacity was more significant than the increase in fan power consumption between transient and steady state PVU operation (34.5 W and $41.4 \mathrm{~W}$ respectively). Therefore, a transient PVU system operating at an average flow rate of $3.5 \mathrm{~L} / \mathrm{s}$ and a frequency of $0.3 \mathrm{~Hz}$ resulted in average energy savings of $15.11 \%$.

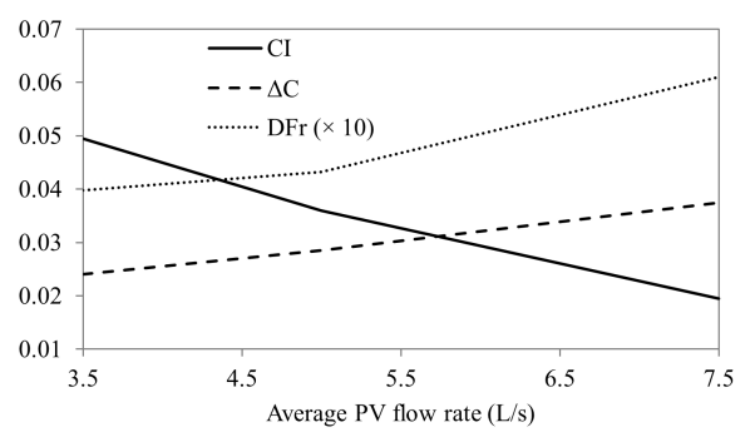

Fig. 6. CI, $\Delta \mathrm{C}$ and $\mathrm{DFr}$ as a function of average PVU flow rate for a PVU frequency of $0.3 \mathrm{~Hz}$.

\section{Conclusion}

A transient validated 3D CFD model was simulated to conduct a study on intermittent PVU assisting a conventional CC system. A parametric study was conducted to investigate the ability of the system confining generated particles to their source while still maitaning comfort of the infected occupant. Results show that an intermittent PVU frequency of $0.3 \mathrm{~Hz}$ and an average flow rate of $3.5 \mathrm{~L} / \mathrm{s}$ confined particles to the infected occupant's microenvironment without compromising their thermal comfort. 


\section{References}

[1] Wang, S., \& Ma, Z. (2008). Supervisory and optimal control of building HVAC systems: A review. $H V A C \& R$ Research, 14(1), 3-32.

[2] Ormstad, H. (2000). Suspended particulate matter in indoor air: adjuvants and allergen carriers. Toxicology, 152(1-3), 53-68.

[3] Davidson, C. I., Phalen, R. F., \& Solomon, P. A. (2005). Airborne particulate matter and human health: a review. Aerosol Science and Technology, 39(8), 737-749.

[4] Novoselac, A., \& Srebric, J. (2002). A critical review on the performance and design of combined cooled ceiling and displacement ventilation systems. Energy and buildings, 34(5), 497-509.

[5] Catalina, T., Virgone, J., \& Kuznik, F. (2009). Evaluation of thermal comfort using combined CFD and experimentation study in a test room equipped with a cooling ceiling. Building and environment, 44(8), 17401750 .

[6] Carbonnier, K., Higgins, C., Bauman, F., Karmann, C., Raftery, P., Schiavon, S., \& Graham, L. T. (2017). Energy Use, Occupant Surveys and Case Study Summary: Radiant Cooling and Heating in Commercial Buildings.

[7] Melikov, A. K. (2016). Advanced air distribution: improving health and comfort while reducing energy use. Indoor air, 26(1), 112-124.

[8] Uğursal, A., \& Culp, C. H. (2013). The effect of temperature, metabolic rate and dynamic localized airflow on thermal comfort. Applied energy, 111, 64-73.

[9] Huang, L., Ouyang, Q., \& Zhu, Y. (2012). Perceptible airflow fluctuation frequency and human thermal response. Building and Environment, 54, 14-19.

[10] Al Assaad, D., Ghali, K., \& Ghaddar, N. (2018). Effectiveness of intermittent personalized ventilation assisting a chilled ceiling for enhanced thermal comfort and acceptable indoor air quality. Building and Environment, 144, 9-22.

[11] Al Assaad, D., Habchi, C., Ghali, K., \& Ghaddar, N. (2018). Effectiveness of intermittent personalized ventilation in protecting occupant from indoor particles. Building and Environment, 128, 22-32.

[12] ANSYS Blog | Engineering Simulation Software News and Insights, (n.d.). https://www.ansys.com/blog/tag/ANSYS HFSS 3D (accessed November 14, 2018).

[13] Hweij, W. A., Ghaddar, N., Ghali, K., \& Habchi, C. (2016). Optimized performance of displacement ventilation aided with chair fans for comfort and indoor air quality. Energy and Buildings, 127, 907-919.

[14] Keblawi, A., Ghaddar, N., Ghali, K., \& Jensen, L. (2009). Chilled ceiling displacement ventilation design charts correlations to employ in optimized system operation for feasible load ranges. Energy and Buildings, 41(11), 1155-1164. 